\title{
American Muslim Immigrant Mental Health: The Role of Racism and Mental Health Stigma
}

\author{
David Phillips, MS
}

Eastern Michigan University

\section{Dean Lauterbach, PhD}

Eastern Michigan University

Correspondence concerning this article should be addressed to David Phillips, Eastern Michigan University, Department of Psychology, 303A Mark Jefferson Science Complex, Ypsilanti, MI 48197. Email: dphill23@emich.edu

\section{Abstract}

Researchers have found that many American Muslim immigrants (AMIs) suffer from mental health problems, and an array of studies have identified racism and mental health stigma as key factors that negatively impact AMI psychological wellbeing. To date, no one has synthesized this literature into a cohesive review. To address this need, we have reviewed literature on racism and mental health stigma using Bronfenbrenner's (1977) Ecological Systems Theory as an intersectional framework. Our findings indicate that AMIs' mental health is impacted by racism and mental health stigma that emanate from distal (i.e., macrosystem) and proximal (i.e., microsystem) settings. We highlight the interactions among these factors, identify gaps in the literature, and detail clinical implications. Specified future directions emphasize the need for more empirical research that considers AMI mental health through a transactional lens.

Keywords: Ecological Systems Theory, Islamophobia, Mental Health Stigma, Muslim immigrants, Muslim Mental Health

American Muslim immigrant (AMI) mental health is an increasingly salient topic that has received comparatively little empirical attention (Abu-Ras et al., 
2010; Ciftci, Jones, \& Corrigan, 2013). Basic epidemiological research indicates that the rate and range of psychological disorders among AMIs are roughly commensurate with the general population (Amer \& Hovey, 2012; Basit \& Hamid, 2010). While there is limited information about the factors contributing to AMI mental health, multiple researchers have implicated racism and mental health stigma as key contributors to AMI psychological health. As these areas of research grow, intersectional reviews are needed to synthesize findings and highlight existing gaps. Such reviews are crucial for informing future research, public policy, and clinical interventions. The present paper addresses this need by using Bronfenbrenner's (1977) Ecological Systems Theory (EST) to synthesize literature on racism and mental health stigma's impact on AMI mental health. The following review presents an overview of Muslims in the USA, introduces EST as an organizational model, and then reviews the literature on racism and mental health stigma.

\section{Muslims in USA}

The Pew Research Center (2007) estimated that there are 2.35 million Muslims in the United States of America. Of this population, 65\% are foreign-born: 24\% from Arab regions, $8 \%$ from Pakistan, 10\% from other South Asian nations, $8 \%$ from Iran, $5 \%$ from Europe, $4 \%$ from African countries excluding North Africa, and 6\% from other countries. More recently, the Pew Research Center (2016) reported that the number of Muslims and the number of Muslim immigrants continue to rise. ${ }^{1}$ In this paper, American Muslim immigrant (AMI) refers to all foreign-born Muslims as well as first- and second-generation offspring (Pew Research Center, 2013). Diverse sub-communities with unique heritages, languages, and religious practices comprise the AMI population (Ahmed \& Reddy, 2007), yet there are common experiences and practices that link most AMIs (Hamid, 2008).

An obvious similarity across Muslim communities is faith in Islam. Muslims view Islam as the last of the Abrahamic religions, which a monotheistic God revealed through the prophet Muhammad (Ahmed \& Reddy, 2007). At the core of Islam are six tenets of faith: 1 ) the belief in the oneness and ultimate nature of Allah; 2) belief in the angels of Allah; 3) belief in all the prophets of Allah throughout time (ending with Muhammad); 4) belief that these prophets' scriptures are revelations from Allah (with the Qur'an being the final rev-

1. Estimates of the U.S. Muslim population vary considerably. Smith's (2002) review of existing sources found marked heterogeneity in methodology, with many sources failing to describe their procedures. At the time of this study, estimates ranged from less that 4 million to over 7 million U.S. Muslims. Despite this incongruence, sources generally agree that the number of AMIs continues to rise. 
elation); 5) belief in the day of judgment; and 6) belief in fate, both in positive and negative events (Jasser, 2008). To remain mindful of these truths, Islam prescribes the following five rituals (i.e., pillars): a) testify that there is no god but God, and Muhammad is God's messenger, b) pray five times a day, c) fast in the month of Ramadan, d) give charity, and e) make a pilgrimage to Mecca at least once. These pillars are practiced by Muslims everywhere (Hamid, 2008).

Beyond core beliefs and practices, AMI communities rely on interpretations of the Quran and hadith to navigate the moral and ethical issues of life, such as conflict management, marriage, and parenting (Ahmed \& Amer, 2012). While there is a diversity of perspectives depending on geographic region, commonalities do exist. For example, AMIs commonly emphasize the central role of the family, with the father at the head of the household and the mother as the primary caregiver (Ahmed \& Amer, 2012). AMIs also attend local mosques and rely on their imam for both spiritual and practical guidance (Abu-Ras, Gheith, \& Cournos, 2008). Regarding education, research indicates that AMIs typically have high education attainment and fall in the middle class socioeconomically (Pew Research Center, 2007). Since the September $11^{\text {th }}$ terrorist attacks, AMIs have shared the unfortunate experience of being the targets of Islamophobia (i.e., negative attitudes and emotions directed at Islam or Muslims; Bleich, 2011), which is covered in further detail in a later section on racism.

This brief review of common factors is not exhaustive. Rather, this section serves to familiarize readers with some of the key commonalties among AMIs, and it is intended to highlight the fact that the lives of AMIs are impacted by a range of variables that go beyond shared religious beliefs. Importantly, these variables interact with each other forming a complex psycho-social milieu. The present paper focuses on two of these factors in particular (i.e., racism and mental health stigma), and utilizes Bronfenbrenner's EST to capture their complex impact on AMI mental health.

\section{Ecological Systems Theory}

Bronfenbrenner developed EST in the late 1970s to offer a coherent developmental paradigm that accounts for the multiple systems that impact human development (Bronfenbrenner, 1977). Specifically, he suggested that an individual's environment is comprised of the following systems nested around the individual: macrosystem, exosystem, mesosytem, and microsystem (Bronfenbrenner, 1979). Although all levels of this model are germane to AMIs, the present study highlights the macrosystem and microsystem in particular. In brief, the macrosystem refers to large-scale ideologies and beliefs, as well as economic, social, education, and political factors. The microsystem refers to 
the individual's immediate or proximal settings; this may include their place of employment, their immediate family, and their place of worship (Bronfenbrenner, 1977; 1979). At the center of these nested systems lies the individual who is impacted by factors from each ecological level.

EST is a multidimensional model that captures both the distal (macrosystem) and proximal (microsystem) factors that impact the individuals' psychological wellbeing, while at the same time emphasizing the importance of the individual's unique characteristics. Though EST was developed decades ago, it has continued to evolve over time and is currently used by a wide array of researchers (Tudge, Mokrova, Hatfield, \& Karnik, 2009). This paper utilizes the original EST framework, as developed in the 1970s, because it is a well-tested, elegant model that captures AMI's complex psycho-social milieu. In particular, the following review evaluates racism and mental health stigma's macrosystem and microsystem impact on AMI mental health using EST.

\section{Racism and mental health}

\section{Terminology selection}

Racism has received decades of empirical attention and has been operationalized as a macrosystem, microsystem, and individual variable (Bonilla-Silva, 1997; Farley, 1988; Kira, Lewandowski, Chiodo, \& Ibrahim, 2014b). Clark, Anderson, Clark, and Williams (1999) defined racism "as beliefs, attitudes, institutional arrangements, and acts that tend to denigrate individuals or groups because of phenotypic characteristics or ethnic group affiliation" (p. 805). Although heterogeneous phenotypically, Islam is a key ethnic characteristic that links diverse AMI communities and multiple authors have endorsed the term racism in AMI research (Abu-Ras et al., 2008; Ahmed, Kia-Keating, \& Tsai, 2011; Rippy \& Newman, 2008; Weatherhead \& Daiches, 2010).

There is also evidence that AMIs experience discrimination based on their physical appearance. For example, both Muslim and non-Muslim Arabs are targeted for their phenotypic characteristics and cultural behaviors, despite the notable differences in their religious beliefs (Ahluwalia \& Pellettiere, 2010)2. Lastly, racism is used here as way of framing other terms, not at their exclusion. Islamophobia is considered a sub-factor of racism and is used throughout this paper. Similarly, discrimination is the behavioral byproduct of racism, not a distinct phenomenon (Bonilla-Silva, 1997; Gee \& Ro, 2009), and racism is a form of oppression (Young, 1995).

2. It may be the case that Asian or South African Muslims are not as frequently victims of racism, but comparative research is not available to analyze this issue. 


\section{Macrosystem racism}

Macrosystem racism refers to the systemic oppression and stratification of non-dominate racial/ethnic groups (Brown, 1998; Nash, 1962; Young, 1995). This phenomenon manifests in ideological forms (such as widely held stereotypes), and institutional forms (such as disparities in health care, education, compensation, legislation, and other resources; Chambers, 2008; Griffith et al., 2007; Jeanquart-Barone \& Sekaran, 1996). Understanding and assessing the impact of macrosystem racism on mental health is a complex task because it is difficult to quantify and distinguish from other variables. Bonilla-Silva (1997) suggested that this partially stems from simplistic theories of racism that often relegate racism research to the individual level. As such, macrosystem racism's impact on mental health is perhaps best understood by enumerating the disparities it creates, including socioeconomic status (SES) inequalities, poor SES mobility, inequalities in living conditions, disparities in resources, and underemployment; all of which correlate with comparatively worse mental health status (Brown, 2003; Kessler et al., 1994; Williams \& Williams-Morris, 2000).

Data gathered over the past decades indicate that AMIs are embedded within a macrosystem that includes ideological and institutional racism. Focusing first on ideological racism, a majority of Americans have endorsed a negative opinion of Muslims since at least the early 1980s (Slade, 1981). But in the wake of the September $11^{\text {th }}$ terrorist attacks, anti-Muslim sentiment, commonly known as Islamophobia, dramatically increased and has remained elevated (CAIR, 2003, 2012). Though it is difficult to record and quantify macrosystem ideologies, stereotypes of Muslims as terrorists, Islam as pathological, assumed cultural homogeneity, and Muslims as exotic have been empirically identified (Nadal, Griffen, Hamit, Leon, \& Tobio, 2012).

Regarding institutional racism, many AMIs have relatively high levels of economic attainment (Amer \& Hovey, 2012; CAIR, 2006), but basic income data does not speak to compensation and employment disparities that emerge when controlling for relevant factors like education attainment. For example, Park, Malachi, Sternin, and Tevet (2009) found that Muslim job candidates were assigned less salary and were presumed to have poorer career trajectories than white candidates in a survey of 67 managers and 82 undergraduates. This phenomenon only emerged in a condition where candidates had slightly negative profiles, which indicates that racism may increase scrutiny (Park et al., 2009). Additionally, research indicates that AMIs perceive disparities in mental health resources, such as a lack of facilities and services located in their communities (Abu-Ras \& Abu-Bader, 2008), but no empirical analyses have attempted to substantiate this impression. Overall, the limited number of studies falls short of truly assessing the depth of institutional racism, but the existing evidence suggests that it exits and may be pernicious (Brown, 1998). 


\section{Microsystem racism}

Data from multiple sources indicate that AMIs have been the target of numerous race-related offenses and these acts of discrimination have occurred within a variety of microsystems including schools, the workplace, political venues, and public service institutions (CAIR, 2012). Specific examples include physical assaults, arson of mosques, verbal assaults, bomb threats, and denial of services (CAIR, 2012; Edwards, 2010; Nadal et al., 2012; Rippy \& Newman, 2006). AMIs have reported a general sense of fear, isolation, and stigmatization following 9/11 (Abu-Ras \& Abu-Bader, 2008; Chand \& Moghadam, 2004). Indeed, researchers have unequivocally demonstrated that AMIs experienced a rise in discrimination after the September $11^{\text {th }}$ attacks (Ahmed \& Reddy, 2007), which was most acute in the year following the events (Kaplan, 2006).

Although AMIs experience relatively high levels of overt discrimination, research suggests that covert or subtle forms of racism, commonly known as microaggressions, account for the largest portion of racist behavior (Young, 1995). Microaggressions refer to brief, commonplace interactions where the perpetrator consciously or subconsciously communicates a hostile, insulting, or negative view of the victim (Constantine \& Sue, 2007). Sue and colleagues (2007) identified micro-insults, micro-assaults, and micro-invalidations as three distinct types of microaggressions; each of which has been linked to negative psychological and physical effects (Sue, 2010).

Three research teams have analyzed microaggressions in AMI communities. Nadal and colleagues (2012) reported that AMI participants $(N=10)$ endorsed experiencing a host of microaggressions, which included mocking of religious garb, unwarranted scrutiny, and being accused of having terrorist connections (among many others). Due to the small sample size and methodology, data on frequency and impact on mental health were not collected. In a related study, Edwards (2010) reported that 55 of 80 AMI participants experienced some form of microaggression, which consistently resulted in feelings of anger and dejection. Lastly, Park, Felix, and Lee (2007) studied implicit negative attitudes toward Muslims on an implicit associations task. Western participants preferred traditionally white-sounding names over Muslim or Arabic names despite denying prejudice on explicit measures. These studies suggest that AMIs are commonly confronted with subtle forms of racism but additional research is needed to examine prevalence and topography.

Racism research has clearly linked microsystem racism to a host of negative mental health outcomes (Kessler, Mickelson, \& Williams, 1999; Landrine \& Klonoff, 1996; Sue, Capudilupo, \& Holder, 2008). Research on AMIs and their communities have mimicked these findings. Perceived racism has been linked to poor mental health and physical health status in AMI communities (Padela \& Heisler, 2010). In particular, feeling less safe following 9/11 predicted 
PTSD in one sample of AMIs living in New York City (Abu-Ras \& Saurez, 2009). Similarly, Amer (2005) reported that perceived degree of marginalization was positively correlated with stress, anxiety, and depression. Counseling utilization data provides additional support for a link between perceived racism and mental health. Following 9/11, utilization of religious counseling for depression, anxiety, and suicidal thoughts rose substantially in a sample of 22 New York City mosques (Abu-Ras et al., 2008). Cause was not directly assessed, but a significant increase in rates of perceived racism was reported.

Multicultural researchers have identified various individual factors that mediate/moderate racism's effect on mental health (Harrell, 2000). Among AMI communities, emerging research has identified four possible mediators. First, Moradi and Hasan (2004) found that perceived level of personal control mediated psychological outcomes in an AMI sample. Second, Edwards (2010) found that participants' level of self-investment in their Muslim communities was the only significant predictor of the relationship between perceived racism and emotional response (i.e., higher identification correlated with worse outcomes). Third, Awad (2010) reported that Muslim participants with higher levels of dominant culture immersion perceived greater levels of discrimination, which indicates that integration and assimilation may lead to worse mental health outcomes in AMI communities. Fourth, internalized mental health stigma has been implicated and is covered in detail below.

\section{Racism summary}

The above review demonstrates that racism is prominent and threatens AMI mental health. At the macrosystem level, AMIs are inlaid within a cultural framework that has become increasingly hostile since the tragic events of September $11^{\text {th }}$, 2001. Racism, though, is more than an abstract force impacting AMIs; it is experienced at a personal level. Mounting data indicates that AMIs can be victims of multiple forms of microsystem racism that have a significant, negative impact on mental health. However, racism does not occur in a vacuum, it is one aspect of AMIs broader ecological system and it is impacted by multiple mediators and moderators. In particular, mental health stigma is a key factor that impacts AMI mental health and interacts with racism. The following section reviews recent mental health stigma literature through the lens of EST.

\section{Mental health stigma and mental health}

Mental health stigma can be defined as the negative attitudes, stereotypes, prejudices, and discrimination associated with having a mental illness (Ciftci et al., 2013). Researchers have identified mental health stigma across multiple 
communities, and have demonstrated a clear link between stigma and mental health (Abdullah \& Brown, 2010; Corrigan, 2004; Corrigan \& Watson, 2007; Kira et al., 2014a). Although mental health stigma is common, the factors that maintain it and how it affects the individual differ by culture and community. Multiple researches, such as Ciftci and colleagues (2013), have written about the particular expression and experience of mental health stigma among AMI communities. A common narrative is that religious explanations of mental illness foster mental health stigma, which in turn compounds psychological problems and causes somatization of psychological distress. The following review organizes and evaluates these claims using EST.

\section{Macrosystem mental health stigma}

Multiple authors assert that religious explanations of mental illness are common among AMIs and directly contribute to mental health stigma. In particular, scholars have reported that AMIs commonly view mental illness as the consequence of a poor relationship with God (Abu-Ras et al., 2008; Joshanloo, 2013; Keshavarzi \& Haque, 2014). Another frequently cited explanation is that evil spirits (known as jinn), black magic, or the evil eye cause(s) mental illness in the religiously weak (Haque, 2004; Islam \& Campbell, 2012). Though these beliefs have been empirically verified across numerous non-US Muslim samples (Al-Adawi et al., 2002; AlKrenawi \& Graham, 1999; El-Islam \& Abu-Dagga, 1992; Kianpoor \& Rhoades, 2006; Tabassum, Macaskill, \& Ahmad, 2000; Weatherhead \& Daiches, 2010), only one researcher has formally studied these beliefs among AMIs. Aloud (2004) found a moderate level of "traditional beliefs" regarding the etiology of mental illness, which included beliefs about possession and religious causes.

As stated, many authors assert that these religious explanations lead to mental health stigma among AMI communities (Aloud, 2004; Joshanloo, 2012; Smither \& Khordandi, 2009). No one has empirically tested this relationship, though Aloud (2004) did find that religious beliefs predicted treatment utilization stigma. Interestingly, there is evidence that some communities reject stigma on the basis of religion, asserting that mental illness, especially severe illness, is Allah's will and within divine control (Vanaleesin, Suttharangsee, \& Hatthakit, 2010). Furthermore, a variety of other causal variables, such as collective trauma, have been suggested to explain stigma (Kira et al., 2014a). Research is immediately needed because identifying macrosystem variables that contribute to mental health stigma could inform treatment and public health initiatives.

Microsystem mental health stigma

Writers from the United States assert that mental health stigma pervades AMI microsystems (Sehwail, Rasras, \& Sehwail, 2013; Shehadeh, 2008), but the only 
empirical evidence comes from international research. In two studies (one from the United Kingdom and one from Ethiopia), a majority of participants endorsed a reluctance to socialize with mentally ill individuals and refused to marry someone with mental illness; participants also indicated that they were stigmatized for having relatives with mental illness (Shibre et al., 2001; Tabassum et al., 2000). In a more extreme example, Ciftci (1999) reported that shame was so strong in a sample of Turkish Muslim families that some decided to remove mentally ill children from society by keeping them housebound (as cited in Ciftci et al., 2013).

Mental health stigma is not only a microsystem variable that leads to aversive interpersonal interactions and family strain, it also impacts individuals views of themselves. Broadly, research indicates that people with mental illness are prone to internalize mental health stigma as self-stigma (Corrigan \& Watson, 2007). Early findings indicate this phenomenon also occurs among AMIs. and colleagues (2014a), using a well-validated measure of self-stigma, found elevated levels of self-stigma among Muslim participants. Furthermore, selfstigma significantly correlated with posttraumatic stress disorder, anxiety, and depression. Conversely, high stigma resistance predicted better mental health functioning (Kira et al., 2014a).

Multiple authors have also advanced the notion that somatoform disorders are common among AMIs (Al-Krenawi \& Graham, 1999; Chaudhury, 2011; Ciftci et al, 2013; Sayed, 2003), and that this is caused, in part, by mental health stigma (Ciftci et al., 2013). Little empirical data exists to substantiate either of these claims. Basit and Hamid (2010) found no evidence of somatization in a sample of 875 AMIs, but somatoform disorders appear prevalent among non-US Muslim samples (Al-Subaie \& Alhamad, 2000; Okasha, 1999). Regarding the link between somatization and stigma, there have been no direct tests of this hypothesis. Additional untested explanations for somatization in AMI communities include heightened awareness of the mind-body connection or language barriers that lead to incorrect diagnoses (Erickson \& Al-Timimi, 2001). More research is critical, as perpetuating unfounded epidemiological assertions and casual explanations may mischaracterize AMIs and foster faulty assumptions by medical and mental health professionals.

\section{Mental health stigma summary}

The impact of mental health stigma is complex. Multiple authors have suggested that common religious beliefs about the etiology of mental illness may influence the stigmatization of mental illness, which in turn impacts expression. The data suggests that religious etiological beliefs and mental health stigma are common across Muslim communities, and may be present among AMIs. Emerging research also suggests that AMIs experience mental health stigma 
(across multiple microsystems) and subsequent self-stigma, but few empirical studies have been conducted. Importantly, the assumption that there is a causal link between these factors and the assertion that AMIs experience higher rates of somatoform disorders remains unsubstantiated. This wealth of assertions amid a dearth of evidence is concerning. Scholars, clinicians, and researchers are encouraged to subject these assumptions to empirical tests. In particular, additional research is needed to assess the magnitude and effect of stigma, to determine the form and prevalence of psychopathology, and to develop culturally informed interventions that address stigma and treat mental illness (Ciftci et al., 2013).

\section{Interaction of racism and mental health stigma}

The preceding review traced racism and mental health stigma from the macrosystem to the microsystem and the individual. As implied by EST, these factors do not operate in isolation; they interact together and with other variables in a complex matrix. Some authors have argued that AMIs experience double stigma, which describes the intersection of mental illness stigma and other forms of stigma like racism or sexism (Gary, 2005). Ciftci and colleagues (2013) argued that AMIs with mental illness experience double stigma due to their psychological status and their ethnicity. The preceding review corroborates this assertion, but research indicates that AMIs may experience more than two sources of stigma.

Specifically, Kira (2001) created the development-based trauma framework (DBTF) to evaluate the compounding effects of different stigmas/traumas. The DBTF specifies three levels of trauma: Type I trauma refers to a single traumatic event (e.g., physical assault), Type II trauma refers a single sequence of traumatic events (e.g., repeated childhood abuse), and Type III trauma refers to chronic sources of trauma like racism, mental health stigma, low socioeconomic status, disability, and gender stigma (Kira, 2004; Kira, Fawzi, \& Fawzi, 2013). Using a sample of 399 participants ( $n=333$ were Muslim) from the ACCESS clinic in Michigan, Kira and colleagues (2014a) reported that internalized stigma of mental illness (i.e., self-stigma) positively correlated with perceived discrimination and poverty. Importantly, self-stigma mediated the effect of perceived discrimination on mental illness (i.e., depression and PTSD), and amplified the effect of poverty on mental illness (Kira et al., 2014a).

These findings highlight the importance of using transactional models to evaluate AMI mental health. Not only did they evaluate a multitude of risk and protective factors, they identified clinically relevant interactions. Their analyses highlighted self-stigma as a crucial treatment target because it mediated and amplified the effect of perceived racism and other risk factors. Although additional research is needed, their research suggests that developing and adminis- 
tering effective treatments to reduce self-stigma may have a broad, ameliorative impact on AMI mental health.

\section{Closing Summary and implications}

Researchers have begun to identify the complex array of factors that impact mental health within AMI communities. Racism and mental health stigma have emerged as key variables, but no one has synthesized these disconnected findings into a transactional framework. Using Bronfenbrenner's EST, this paper tied together the extant literature into a coherent narrative highlighting key findings and current gaps. Based on the current data, it is clear that macrosystem and microsystem racism is prevalent and that it has deleterious mental health consequences. Similarly, mental health stigma exists and the internalization of this stigma is common and has profoundly negative effects on AMI mental health. Current gaps in this literature were specified throughout, but key issues include the prevalence and form of institutional racism and the nature of the relationships between religious explanations for mental illness, stigma, and somatization.

\section{Limitations}

The primary limitation of the present paper is the search method. Studies were located using common databases (e.g., Proquest, PsychINFO, PsycARTICLES, Google Scholar), relevant journals (e.g., Journal of Muslim Mental Health), and published books. This approach produced a sizeable number of documents, which were thoroughly reviewed. Yet, this paper does not qualify as a formal systematic review, because the authors did not utilize an exhaustive search method, such as the PRISMA guidelines (Moher, Liberati, Tetzlaff, Altman, \& Prisma Group, 2009). As such, it is possible that some studies were missed. Furthermore, attempts were made to locate all dissertations and theses, but occasionally these works could not be retrieved even when contacting the authors directly.

\section{Implications and future directions}

The key implication of this review is that empirically informed treatments and public health initiatives are immediately needed. Researchers have identified racism and mental health stigma as pernicious factors, and most conclude their research with recommendations to consider these factors in treatment. Yet, no interventions have been formally developed or tested. Similarly, it is unclear if treatments deemed efficacious for use with western cohorts are appropri- 
ate for AMIs. Given this dearth of research and the treatment needs of AMI communities, empirically tested interventions and public health initiatives are immediately needed to ensure that AMIs receive effective, culturally tailored treatment.

Furthermore, this paper encourages researchers to consider AMI mental health through a transactional lens, such as EST. The present review located only one research team that has utilized such an approach and their results highlight the valuable information that can be gleaned from such an analysis. Specifically, Kira and colleagues (2014a) employed hierarchical modeling to test various hypotheses based on the Development-Based Trauma Framework. Hierarchical analysis helped pinpoint self-stigma as a mediator of perceived discrimination. No other researchers have tested complex interactional relationships among AMIs. This is unfortunate, because the present review suggests that AMI mental health is impacted by multiple interacting distal and proximal variables. Understanding these variables, their relationships, and their impact on AMI mental health is far more than an academic exercise, it is crucial for the development of effective public health initiatives and therapeutic interventions.

\section{References}

Abdullah, T., \& Brown, T. L. (2010). Mental illness stigma and ethnocultural beliefs, values, and norms: An integrative review. Clinical Psychology Review, 31, 934-948. https://doi.org/10.1016/j.cpr.2011.05.003

Abu-Ras, W., \& Abu-Bader (2008). The impact of the September 11, 2001 attacks on the well-being of Arab Americans in New York city. Journal of Muslim Mental Health, 3, 217-239. https://dx.doi.org/10.1080/15564900802487634

Abu-Ras, W., Ali, O. M., Ansari, B., Hamid, H., Haque, S., Mahmood, O., et al. (2010). Addressing mental health issues among American Muslims in the military. Institute for Social Policy and Understanding. Retrieved from https://www.ispu.org/ addressing-health-issues-among-american-muslims-in-the-military/

Abu-Ras, W., Gheith, A., \& Cournos, F. (2008). The imam's role in mental health promotion: A study at 22 mosques in New York City's Muslim community. Journal of Muslim Mental Health, 3, 155-176. https://dx.doi.org/10.1080/15564900802487576

Abu-Ras, W. M., \& Suarez, Z. E. (2009). Muslim men and women's perception of discrimination, hate crimes, and PTSD symptoms post 9/11. Traumatology, 15(3), 48-63. https://dx.doi.org/10.1177/1534765609342281

Ahluwalia, M. K., \& Pellettiere, L. (2010). Sikh men post-9/11: Misidentification, discrimination, and coping. Asian American Journal of Psychology, 1(4), 303-314. https://dx.doi.org/10.1037/a0022156

Ahmed, S., \& Amer, M. M. (2012). Counseling Muslims: Handbook of mental health issues and interventions. New York, NY: Routledge.

Ahmed, S. R., Kia-Keating, M., \& Tsai, K. H. (2011). A structural model of racial discrimination, acculturative stress, and cultural resources among Arab American 
adolescents. American Journal of Community Psychology, 48, 181-192. https:// dx.doi.org/10.1007/s10464-011-9424-3

Ahmed, S., \& Reddy, L. A. (2007). Understanding the mental health needs of American Muslims: Recommendations and considerations for practice. Journal of Multicultural Counseling and Development, 35, 207-218. https://dx.doi.org/10.1002/j.21611912.2007.tb00061.x

Al-Adawi, S., Dorvlo, A. S. S., Al-Ismaily, S. S., Al-Ghafry, D. A., Al-Noobi, B. Z., Al-Salmi, A., et al. (2002). Perception of and attitude towards mental illness in Oman. International Journal of Social Psychiatry, 48(4), 305-317. https://dx.doi. org/10.1177/002076402128783334

Al-Krenawi, A., \& Graham J. R. (1999). Gender and Biomedical/ Traditional Mental Health Utilization Among the Bedouin-Arabs of Negev. Cultural, Medicine and Psychiatry 23, 219-243. https://dx.doi.org/10.1023/A:1005455809283

Aloud, N. (2004). Factors affecting attitudes toward seeking and using formal mental health and psychological services among Arab-Muslims population. Retrieved from The Ohio State University Electronic Theses \& Dissertations Center. https://etd. ohiolink.edu/rws_etd/document/get/osu1078935499/inline

Al-Subaie, A., \& Alhamad, A. (2000). Psychiatry in Saudi Arabia. In I. Al-Issa (Ed.), Al-Junun: Mental illness in the Islamic world (pp. 205-234). Madison, CT: International Universities Press.

Amer, M. M. (2005). Arab American mental health in the post September 11 era: Acculturation, stress, and coping. Retrieved at The University of Toledo Digital Repository. https://utdr.utoledo.edu/cgi/viewcontent.cgi?article=2424\&context=thesesdissertations

Amer, M. M., \& Hovey, J. D. (2012). Anxiety and depression in a post-September 11 sample of Arabs in the USA. Social Psychiatry and Psychiatric Epidemiology, 47, 409-418. https://dx.doi.org/10.1007/s00127-011-0341-4

Awad, G. H. (2010). The impact of acculturation and religious identification on perceived discrimination for Arab/Middle Eastern Americans. Cultural Diversity and Ethnic Minority Psychology, 16(1), 59-67. https://dx.doi.org/10.1037/a0016675

Basit, A., \& Hamid, M. (2010). Mental health issues of Muslim Americans. Journal of Islamic Medical Association of North America, 42, 106-110. https://dx.doi. org/10.5915/42-3-5507

Bleich, E. (2011). What is Islamophobia and how much is there? Theorizing and measuring an emerging comparative concept. American Behavioral Scientist, 55, 1581 1600. https://dx.doi.org/10.1177/0002764211409387

Bonilla-Silva, E. (1997). Rethinking racism: Toward a structural interpretation. American Sociological Review, 62(3), 465- 480. https://doi.org/10.2307/2657316

Bronfenbrenner, U. (1977). Toward an experimental ecology of human development. American Psychologist, 32, 513-531. https://dx.doi.org/10.1037/0003066X.32.7.513

Bronfenbrenner, U. (1979). The ecology of human development. Cambridge, MA: Harvard University Press.

Brown, T. N. (1998). The mental health consequences of racial stratification among African-Americans and white Americans in Detroit, Michigan. Retrieved from ProQuest Dissertations \& Theses.

Brown, T. N. (2003). Critical race theory speaks to the sociology of mental health: Mental health problems produced by racial stratification. Journal of Health and Social Behavior, 44, 292-301. https://doi.org/10.2307/1519780 
Chambers, C. (2008). Institutional racism: Is law used as a tool to perpetuate racial inequality? Retrieved from North Carolina State University Institutional Repository. https://repository.lib.ncsu.edu/handle/1840.16/3654

Chand, I. A., \& Moghadam, S. (2004). Depression and fear among Muslim families in southern California. Studies in Islam and the Middle East Journal, 1(2). Retrieved from https://pdfs.semanticscholar.org/6935/9d6d6b86d87ad4be76398277e6cadb e5f2b3.pdf

Chaudhury, S. R. (2011). Attitudes towards the diagnosis and treatment of depression among South Asian Muslim Americans. Retrieved from ProQuest Dissertations \& Theses.

Ciftci, A., Jones, N., \& Corrigan, P. W. (2013). Mental health stigma in the Muslim community. Journal of Muslim Mental Health, 7(1), 17-32. http://dx.doi.org/10.3998/ jmmh.10381607.0007.102

Clark, R., Anderson, N. B., Clark, V. R., \& Williams, D. R. (1999). Racism as a stressor for African Americans: A biopsychosocial model. American Psychologist, 54, 805816. https://doi.org/10.1037//0003-066x.54.10.805

Constantine, M. G., \& Sue, D. W. (2007). Perceptions of racial microaggressions among black supervisees in cross-racial dyads. Journal of Counseling Psychology, 54(2), 142-153. https://doi.org/10.1037/0022-0167.54.2.142

Corrigan, P. W. (2004). How stigma interferes with mental health care. American Psychologist, 59, 614-625. https://doi.org/10.1037/0003-066x.59.7.614

Corrigan, P. W., \& Watson, A. C. (2007). The stigma of psychiatric disorders and the gender, ethnicity, and education of the perceiver. Community Mental Health Journal, 43, 439-458. https://doi.org/10.1007/s10597-007-9084-9

Council on American-Islamic Relations. (2003). The status of Muslim civil rights in the United States 2002: Stereotypes and Civil Liberties. Washington, DC: CAIR. Retrieved from https://www.cair.com/civil-rights/civil-rights-reports/12-civilrights/11728-2002-civil-rights-report-stereotypes-and-civil-liberties.html

Council on American-Islamic Relations. (2006). Western Muslim minorities: Integration and disenfranchisement. Washington, DC: CAIR. Retrieved from https:// www.cair.com/images/pdf/policy_bulletin_Integration_in_the_West.pdf

Council on American-Islamic Relations. (2012). Legislating fear: Islamophobia and Its Impact in the United States. Washington, DC: Retrieved from https://www.cair. com/images/pdf/2010-Islamophobia-Report.pdf

Edwards, R. (2010). Religious microaggressions towards Muslims in the United States: Group identity and self-esteem as predictors of affective responses. Retrieved from Wesleyan University digital repository https://wesscholar.wesleyan.edu/cgi/viewcontent.cgi? article $=1456 \&$ context=etd_hon_theses

El-Islam, M. F., \& Abu Dagga, S. I. (1992). Lay explanation of symptoms of mental ill health in Kuwait. International Journal of Social psychiatry, 38, 150-156. https:// doi.org/10.1177/002076409203800208

Erickson, C. D., \& Al-Timmi, N. R. (2001). Providing mental health services to Arab Americans: Recommendations and considerations. Cultural Diversity and Ethnic Minority Psychology, 7, 308-327. https://doi.org/10.1037//1099-9809.7.4.308

Farley, J. E. (1988). Orientation: Basic terms and concepts. In J. E. Farley (Ed.), Majorityminority relations ( $2^{\text {nd }}$ ed., pp. 1-11) Englewood Cliffs, NJ: Prentice Hall.

Gary, F. A. (2005). Stigma: Barrier to mental health care among ethnic minorities. Issues in Mental Health Nursing, 26, 979-999. https://doi.org/10.1080/01612840500280638

Gee, G. \& Ro, A. (2009). Racism and discrimination. In C. Trihn-Shevrin, N. S. Islam, 
\& M. J. Rey (Eds.), Asian American communities and health: Context, research, and action (pp. 364-402). San Francisco, CA: John Wiley \& Sons.

Griffith, D. M., Mason, M., Yonas, M., Eng, E., Jeffries, V., Plihcik, S., et al. (2007). Dismantling institutional racism: Theory and action. American Journal of Community Psychology, 39, 381-392. https://doi.org/10.1007/s10464-007-9117-0

Hamid, H. (2008). Basic history and tenets of Islam. In S. Akhtar (Ed.), The crescent and the couch: Cross-currents between Islam and psychoanalysis (pp. 3-19). New York, NY: Aronson.

Haque, A. (2004). Religion and mental health: The case of American Muslims. Journal of Religion and Health, 43(1), 45-58. https://doi.org/10.1023/ b:jorh.0000009755.25256.71

Harrell, S. P. (2000). A multidimensional conceptualization of racism-related stress: Implications for the well-being of people of color. American Journal of Orthopsychiatry, 70(1), 42-57. https://doi.org/10.1037/h0087722

Islam, F., \& Campbell, R. A. (2012). "Satan has afflicted me!" Jinn possession and mental illness in the Qur'an. Journal of Religious Health, 53, 229-243. https://doi. org/10.1007/s10943-012-9626-5

Jasser, S. (2008). Islam and family structure. In S. Akhtar (Ed.), The crescent and the couch: Cross-currents between Islam and psychoanalysis (pp. 123-139). New York, NY: Aronson.

Jeanquart-Barone, S., \& Sekaran, U. (1996). Institutional racism: An empirical study. Journal of Social Psychology, 136, 477-482. https://doi.org/10.1080/00224545.1996 .9714029

Joshanloo, M. (2012). A comparison of western and Islamic conceptions of happiness. Journal of Happiness Studies, 14, 1857-1874. https://doi.org/10.1007/s10902-0129406-7

Joshanloo, M. (2013). Eastern conceptualizations of happiness: Fundamental differences with western views. Journal of Happiness Studies. Retrieved from http://link. springer.com/article/10.1007/s10902-013-9431-1.

Kaplan, J. (2006). Islamophobia in America? September 11 and Islamophobic hate crime. Terrorism and Political Violence, 18, 1-33. https://doi. org/10.1080/09546550500383209

Keshavarzi, H., \& Haque, A. (2014). Outlining a psychotherapy model for enhancing Muslim mental health within an Islamic context. International Journal for the Psychology of Religion, 23, 230-249. https://doi.org/10.1080/10508619.2012.712000

Kessler, R. C., McGonagle, K. A., Zhao, S., Nelson, C. B., Hughes, M., Eshleman, S. et al. (1994). Lifetime and 12-month prevalence of DSM-III-R psychiatric disorders in the United States: Results from the National Comorbidity Survey. Archives of General Psychiatry, 51(1), 8-19. https://doi.org/10.1001/archpsyc.1994.03950010008002

Kessler, R. C., Mickelson, K. D., \& Williams, D. R. (1999). The prevalence, distribution, and mental health correlates of perceived discrimination in the United States. Journal of Health and Social Behavior, 40, 208-230. https://doi.org/10.2307/2676349

Kianpoor, M., \& Rhoades Jr., G. F. (2006). "Djinnati": A possession state in Baloochistan, Iran. Journal of Trauma Practice, 4, 147-155. https://doi.org/10.1300/ j189v04n01_10

Kira, I. (2001). Taxonomy of trauma and trauma assessment. Traumatology, 2, 1-14. https://doi.org/10.1177/153476560100700202

Kira, I. (2004). Secondary trauma in treating refugee survivors of torture and their families. Torture, 14, 38-44. https://doi.org/10.1037/e315822004-001 
Kira, I., Fawzi, M., \& Fawzi, M. (2013). The dynamics of cumulative trauma and trauma types in adults patients with psychiatric disorders: Two cross-cultural studies. Traumatology, 19, 179-195. https://doi.org/10.1037/e659772012-001

Kira\{ ? MH: There are 22014 Kira et al. articles. Please verify that references to these are clear from the content - otherwise, differentiate them as Kira et al. (2014a) and (2014b)I adjusted this throughout the document.\}, I. A., Lewandowski, L., Ashby, J. S., Templin, T., Ramaswamy, V., \& Mohanesh, J. (2014a). The Traumatogenic dynamics of internalized stigma of mental illness among Arab American, Muslim, and refugee clients. Journal of the American Psychiatric Nurses Association, 20(4), 250-266. https://doi.org/10.1177/1078390314542873

Kira, I. A., Lewandowski, L., Chiodo, L., \& Ibrahim, A. (2014b). Advances in systemic trauma theory: Traumatogenic dynamics and consequences of backlash as a multi-systemic trauma on Iraqi refugee Muslim adolescents. Psychology, 5, 389412. https://doi.org/10.4236/psych.2014.55050

Landrine, H., \& Klondoff, E. A. (1996). The schedule of racist events: A measure of racial discrimination and a study of its negative physical and mental health consequences. Journal of Black Psychology, 22(2), 144-168. https://doi. org/10.1177/00957984960222002

Moher, D., Liberati, A., Tetzlaff, J., Altman, D. G., \& Prisma Group. (2009). Preferred reporting items for systematic reviews and meta-analyses: The PRISMA statement. PLoS med, 6(7), e1000097. https://doi.org/10.1371/journal.pmed.1000097

Moradi, B., \& Hasan, N. T. (2004). Arab-American persons' reported experiences of discrimination and mental health: The mediating role of personal control. Journal of Counseling Psychology, 51, 418-428. https://doi.org/10.1037/0022-0167.51.4.418

Nadal, K. L., Griffin, K. E., Hamit, S., Leon, J. \& Tobio, M. (2012). Subtle and overt forms of Islamophobia: Microagressions toward Muslim Americans. Journal of Muslim Mental Health, 6(2), 15-38. https://doi.org/10.3998/jmmh.10381607.0006.203

Nash, M. (1962). Race and the ideology of race. Current Anthropology, 3(3), 285-288. http://www.journals.uchicago.edu/doi/abs/10.1086/200294?journalCode=ca

Okasha, A. (1999). Mental Health in the Middle East. An Egyptian perspective. Clinical Psychology Review, 19, 917-933. https://doi.org/10.1016/s0272-7358(99)00003-3

Padela, A. I., \& Heisler, M. (2010). The association of perceived abuse and discrimination after September 11, 2001, with psychological distress, level of happiness, and health status among Arab Americans. American Journal of Public Health, 100(2), 284-291. https://doi.org/10.2105/ajph.2009.164954

Park, J., Felix, K., \& Lee, G. (2007). Implicit attitudes toward Arab-Muslims and the moderating effects of social information. Basic and Applied Social Psychology, 29, 35-45. https://doi.org/10.1080/01973530701330942

Park, J., Malachi, E., Sternin, O., \& Tevet, R. (2009). Subtle bias against Muslim job applicants in personnel decisions. Journal of Applied Social Psychology, 39(9), 21742190. https://doi.org/10.1111/j.1559-1816.2009.00520.x

Pew Research Center. (2007). Muslim Americans: Middle class and mostly mainstream. Retrieved from http://www.pewresearch.org/2007/05/22/muslim-americansmiddle-class-and-mostly-mainstream/

Pew Research Center (2013). Second-Generation Americans: A portrait of the adult children of immigrants. Retrieved from http://www.pewsocialtrends.org/2013/02/07/ second-generation-americans/

Pew Research Center (2016). A new estimate of the U.S. Muslim population. http:// 
www.pewresearch.org/fact-tank/2016/01/06/a-new-estimate-of-the-u-s-muslimpopulation/

Rippy, A. E., \& Newman, E. (2006). Perceived religious discrimination and its relationship to anxiety and paranoia among Muslim Americans. Journal of Muslim Mental Health, 1, 5-20. https://doi.org/10.1080/15564900600654351

Rippy, A. E., \& Newman, E. (2008). Adaptation of a scale of race-related stress for use with Muslim Americans. Journal of Muslim Mental Health, 3, 53-68. https://doi. org/10.1080/15564900802035292

Sayed, M. A., (2003). Conceptualization of mental illness within Arab cultures: Meeting challenges in cross-cultural settings. Social Behavior and Personality, 31, 333342. https://doi.org/10.2224/sbp.2003.31.4.333

Sehwail, M., Rasras, K., \& Sehwail, W. (2013). Public attitudes and perceptions of mental health in the Palestinian community. ACCESS Health Journal, 2, 140-147. https://accesscommunity.org/sites/default/files/documents/access6thhealthjournalproceedings3.pdf

Shehadeh, S. (2008). A psychoanalytic exploration into the Arab self and implications for therapy with Arabs in the United States. Retrieved from ProQuest Dissertations and Theses.

Shibre, T., Negash, A., Kullgren, G., Kebede, D., Alem, A., Fekadu, A., et al. (2001). Perception of stigma among family members of individuals with schizophrenia and major affective disorders in rural Ethiopia. Social Psychiatry and Psychiatric Epidemiology, 36, 299-303. https://doi.org/10.1007/s001270170048

Slade, S. (1981). The image of the Arab in America: Analysis of a poll on American attitudes. Middle East Journal, 35(2), 143-162. http://www.jstor.org/stable/4326196

Smith, T. W. (2002). Review: The Muslim population of the United States: The methodology of estimates. The Public Opinion Quarterly, 66, 404-417. http://www.jstor. org/stable/3078769

Smither, R., \& Khordandi, A. (2009). The implicit personality theory of Islam. Psychology of Religion and Spirituality, 1, 81-96. https://doi.org/10.1037/e696542007-001

Sue, D. W. (Ed.). (2010). Microaggressions and marginality: Manifestation, dynamics, and impact. Hoboken, NJ: John Wiley \& Sons.

Sue, D. W., Capodilupo, C. M., \& Holder, A. M. (2008). Racial microaggressions in the life experience of Black Americans. Professional Psychology: Research and Practice, 39(3), 329-336. https://doi.org/10.1037/0735-7028.39.3.329

Sue, D. W., Capodilupo, C. M., Torino, G. C., Bucceri, J. M., Holder, A. M., Nadal, K. L., et al. (2007). Racial microaggressions in everyday life: Implications for clinical practice. American Psychologist, 62(4), 271-286. https://doi.org/10.1037/0003066x.62.4.271

Tabassum, R., Macaskill, A., \& Ahmad, I. (2000). Attitudes towards mental health in an urban Pakistani community in the United Kingdom. International Journal of Social Psychiatry, 46(3), 170-181. https://doi.org/10.1177/002076400004600303

Tudge, J. R. H., Mokrova, I., Hatfield, B. E., \& Karnik, R. B. (2009). Uses and misuses of Bronfenbrenner's bioecological theory of human development. Journal of Family Theory and Review, 1, 198-210. https://doi.org/10.1111/j.1756-2589.2009.00026.x

Vanaleesin, S., Suttharangsee, W., \& Hatthakit, U. (2010). Cultural aspects of care for Muslim schizophrenic patients: An ethnonursing study. Songklanagarind Medical Journal, 25, 361-370. http://medinfo.psu.ac.th/smj2/25_5/pdf25-5/01srisuda.pdf

Weatherhead, S., \& Daiches, A. (2010). Muslim views on mental health and psycho- 
therapy. Psychology and Psychotherapy: Theory, Research, and Practice, 83, 75-89. https://doi.org/10.1348/147608309x467807

Williams, D. R., \& Williams-Morris, R. (2000). Racism and mental health: The African American experience. Ethnicity and Health, 5(3/4), 243-268. https://doi. org/10.1080/713667453

Young, M. (1995). Five faces of oppression. In D. A. Harris (Ed.), Multiculturalism from the margins: Non-dominant voices of difference and diversity (pp. 65-86). Westport, Connecticut: Bergin and Garvey. 